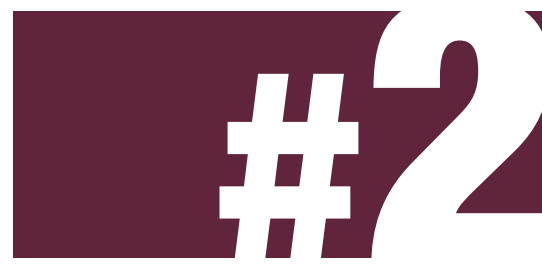

ESPECIAL DIVERSIDADE E GESTÃO

\title{
MULHERES CIENTISTAS: EXCEÇÃO ATÉ QUANDO?
}

APESAR DE SUA EMANCIPAÇÃO E CONQUISTAS NOS ÚLTIMOS CEM ANOS, AS MULHERES AINDA SOFREM COM ESTEREÓTIPOS E PRECONCEITOS NO MEIO ACADÊMICO. MULHERES CIENTISTAS AINDA SÃO MINORIA, MESMO EM PAÍSES DESENVOLVIDOS M MARIA ESTER DE FREITAS, professora da FGV-EAESP, ester.freitas@fgv.br

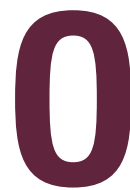
século 20 foi marcado por muitos acontecimentos dignos dos grandes compêndios históricos. Aqui nos reportaremos brevemente a um deles, que ainda está em andamento, envolve diretamente metade da população do planeta e tem influenciado substancialmente a vida da outra metade: a revolução silenciosa das mulheres, que tem permitido o reconhecimento, de direito, de um enorme segmento que sempre contribuiu de fato para a constituição da sociedade.

\section{VOZ ATIVA}

O balanço atualizado dessa revolução é multifacetado. Em primeiro lugar, tivemos um grande salto no grau de escolaridade feminina. Por sinal, além de terem conseguido acesso à escolarização formal, as mulheres apresentam índices maiores que os homens no que se refere à conclusão dos cursos: não apenas começam cursos, como costumam terminá-los, habilitando-se para outros, mais elevados. Um segundo aspecto é o aumento, em volume e 
diversificação, da sua participação no mundo do trabalho. Se há cem anos eram algumas poucas operárias, hoje elas ocupam todos os cargos, inclusive nas mais altas posições da vida econômica e política de países ocidentais, começando a reivindicar essas oportunidades também em outras sociedades, mais conservadoras e menos democráticas.

Além disso, mulheres passaram a exercer o poder de sujeito de suas próprias vidas, em questões relacionadas a casamento, filhos, carreira, controle de tempo, viagens, planejamento financeiro etc. Se antes elas eram quando muito consultadas, hoje têm uma participação ativa nas decisões importantes. Adquiriram consciência de seu papel como cidadãs e membros de uma sociedade da qual participam, na qual têm direitos e da qual merecem reconhecimento explícito e respeito por parte de políticas públicas.

Em síntese, essa revolução teve como mote a igualdade de oportunidades. Convém ressaltar que se trata de um conceito político e não biológico, afinal a natureza criou dois seres humanos diferentes, inteiros, absolutos e conscientes de si, mas foi a construção histórica e cultural que se encarregou de considerar o homem como o padrão e a mulher como "o outro".

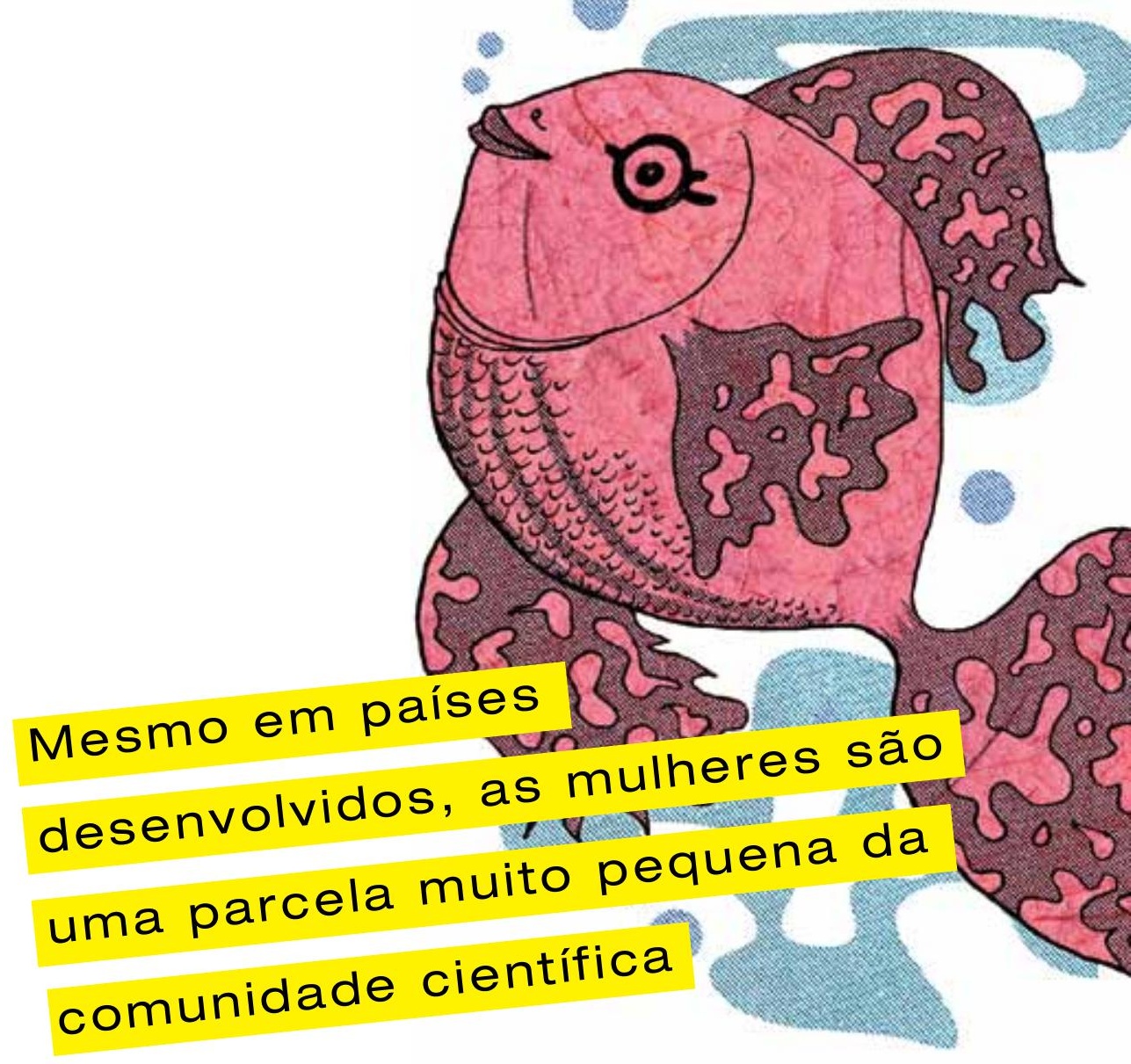

\section{IGUALDADE DE OPORTUNIDADES}

Investidas dos novos poderes duramente conquistados, as mulheres podem ser hoje, em tese, o que quiserem: donas de casa, executivas, maestrinas, médicas, engenheiras, advogadas, secretárias, juízas, astronautas, enfermeiras, prostitutas, policiais etc. Embora muitos trabalhos sejam corriqueiros, mal pagos e pouco qualificados, trata-se de uma condição que afeta também a muitos homens. Agora as mulheres também estão trabalhando nos confins da terra, como membros de equipes de cientistas que desbravam a Antártida, e nos confins do espaço, ajudando a construir a estação científica internacional. Esses são dois símbolos atuais do trabalho desafiante e qualificado, redutos - até bem pouco tempo - considerados exclusivamente masculinos.

Mas tudo se passa às mil maravilhas? Com certeza não. Problemas fazem parte da realidade, e lutar para resolvê-los é uma constante na vida. Um exemplo disso, entre tantos outros possíveis, pôde ser visto nos jornais brasileiros no primeiro semestre deste ano, a respeito do gabinete escolhido pela presidente Dilma, qualificado de "ministério das luluzi- 
nhas". Alguém disse alguma coisa quando o ministério era constituído apenas por homens? Mas o importante é que as mulheres não têm desistido porque têm de enfrentar preconceitos ou tons jocosos.

\section{A CIENTISTA}

Detentoras de maiores qualificações profissionais e investidas do poder de determinar sua vida, as mulheres têm optado por caminhos múltiplos, que vão desde os mais tradicionais aos mais ousados. O marcante nesta discussão é o fato de se tratar de escolhas feitas por elas e não por seus maridos, pais ou "responsáveis". Exploraremos aqui alguns aspectos da carreira intelectual exercida pelas mulheres.

Em princípio, a atividade intelectual é própria do ser humano, e somos todos dotados de diferentes tipos de inteligência que nos permitem fazer elaborações mentais, compreender situações, gerar alternativas e agir em consequência.

Podemos falar, dentre outras, da inteligência prática, que se encarrega dos processos de adaptação às situações e condições contextuais; da inte- ligência artesanal, que nos permite inventar e criar coisas a partir de outras coisas; e da inteligência lógica e racional, que nos capacita a construir abstrações como conceitos, teorias e símbolos. Hoje em dia é ponto pacífico que não existe diferença entre o nível de inteligência geral de homens e mulheres, ainda que existam, sim, diferenças entre as habilidades desenvolvidas por uns e pelas outras. Habilidades, sabemos, são construídas a partir de estímulos, curiosidades, interesses e treino.

O trabalho intelectual, e em especial o trabalho científico, é movido a inteligência, conhecimento, criatividade, persistência, imaginação, disciplina e interlocução. Nenhum desses atributos é monopólio dos homens. A breve história social da mulher no campo científico mostra que ela teve que enfrentar poderosos inimigos, tais como a igreja, a medicina, muitos filósofos, a aristocracia, as universidades e as academias científicas. Ao longo do tempo, mulheres foram impedidas de estudar, de frequentar universidades e cursos. Outras foram, simplesmente, apagadas da história da ciência.

Pesquisas norte-americanas e europeias atuais, em universidades de grande prestígio, como o MIT e Harvard, revelam a existência de mecanismos institucionais discriminatórios e sexistas que impõem às cientistas a estagnação na carreira, cobrando-as por desempenhos muito superiores aos de seus pares homens para os mesmos benefícios e cargos; ademais, revelam que o acesso à carreira, sobretudo nas ciências exatas, é extremamente restritivo e pouco incentivado, o que explica o quadro mundial de pouca participação das mulheres nesse campo, mesmo nos países desenvolvidos, onde elas representam entre $4 \%$ e $8 \%$ dos acadêmicos.

O Brasil reproduz mais ou menos a mesma situação, conforme os poucos estudos feitos sobre o assunto. Aqui também é perceptível o fato de que, apesar da presença significativa de mulheres nos cursos de graduação e pós-graduação, elas dificilmente chegam às posições acadêmicas mais elevadas ou de maior prestígio na carreira ou nos órgãos de fomento à pesquisa e comitês científicos. Quantas cientistas no Brasil assumiram a posição mais elevada na Capes ou no CNPq? Quantas assumiram a presidência da 
Academia Brasileira de Ciências? Quantas assumiram diretorias das fundações estaduais de pesquisa? Qual a participação delas nos comitês de pesquisa dessas diferentes entidades?

\section{DESCULPAS E PRECONCEITO}

As justificativas para esse quadro encontram mais ou menos o mesmo caminho de sempre: cabe à mulher a responsabilidade pelo dia a dia da família; o relógio biológico da maternidade é sincronizado com o relógio do investimento na carreira; a mulher é cobrada para se ajustar às demandas da profissão do parceiro, relegando as próprias a segundo plano; existe reduzido número de mulheres em cargos decisórios, o que cria um círculo vicioso, dificultando a implantação de políticas de estímulo e o reconhecimento do problema pela própria comunidade científica que ocupa cargos dirigentes etc.

Em 2006, o reitor da Universidade Harvard, Larry Summers, teve que se demitir do cargo em virtude de uma declaração sua, de 2005, de que as diferenças inatas entre homens e mulheres eram um dos fatores que justificavam o fato de poucas mulheres terem êxito em carreiras na ciência e na matemática. O fato levantou poeira e provocou um enorme vespeiro. A própria Harvard, após o episódio, elaborou um projeto para incentivar maior diversidade no seu quadro docente, e nomeou uma reitora.

\section{CIENTISTAS BRASILEIRAS}

O Brasil tem evoluído bastante nos últimos anos, tanto em relação à participação feminina no corpo discente das universidades em todas as áreas, como em seu quadro docente, em um contexto em que o volume e impacto da produção científica dos países passa a ser visto como o grande diferencial entre os que estão dentro e fora do clube dos que importam.
Para que as novas gerações possam ter o seu potencial mais bem aproveitado - e a comunidade científica brasileira possa fazer parte desse clube -, é imprescindível atravessar a barreira dos preconceitos e incentivar nossas crianças, de qualquer sexo, a desenvolver todas as suas capacidades, habilidades e inteligências. Com isso, não apenas reagiremos a um possível apagão na ciência brasileira, mas construiremos uma mentalidade que respeitará uma menina quando for questionada: "O que você quer ser quando crescer?", e ela responder: "Uma cientista". Não é querer demais, já estivemos muito mais longe.

\footnotetext{
O Brasil tem avançado nos

últimos anos, mas ainda

há muitos preconceitos a

serem quebrados
} 